\title{
The Knowledge of Local Communities and School Knowledge: In Search of a Didactic Transposition in Natural Sciences
}

\author{
Jó António Capece ${ }^{1,2}$ \\ ${ }^{1}$ Department of Physics, Faculty of Natural Sciences and Mathematics, Pedagogical University, Mozambique \\ ${ }^{2}$ Faculty of Sciences of Education and Psychology (FACEP), Pedagogical University, Mozambique
}

Copyright $\bigcirc 2018$ by authors, all rights reserved. Authors agree that this article remains permanently open access under the terms of the Creative Commons Attribution License 4.0 International License

\begin{abstract}
This article is the result of an ongoing research under the project entitled 'The local curriculum in Mozambican schools: epistemological and didactic-methodological strategies for its implementation'. Based on ethnographic research, the collection is being made. Systematization of knowledge and cultural experiences of local communities are also collected in the three regions of Mozambique (North, Centre and South) seeking their appreciation to Local Curriculum component. The overall objective of the study is to analyze production processes and legitimization of local community knowledge, in search of elements for a 'didactic transposition', specifically in the teaching of Natural Sciences. Preliminary results of the research point to the existence of sufficient evidence to support the hypothesis of inclusion of local community knowledge in school content. Thus, we suggest that strategies are established involving the training of teachers, the adoption of educational policies that give priority to local knowledge and the use of appropriate methodologies that underlie the deepening and extension.
\end{abstract}

Keywords Local Knowledge, Local Communities, Didactic transposition, School Knowledge, Teacher Training - Mozambique

\section{Introduction}

Within implementation of the project on "The local curriculum in Mozambican schools: epistemological and didactic-methodological strategies of its implementation," the Pedagogical University is conducting research that aims to:

a) Collect and systematize the knowledge and cultural experiences of communities for their use in Mozambican schools; b) Analyze production processes and legitimization of local knowledge in local communities and

c) Search foe elements for a "didactic transposition" in the transmission of the local curriculum content;

Thus, on the basis of ethnographic line methodology, we carried out a field work in Maputo province, particularly in the districts of Magude (northern area), Manhiça/Kalanga (central area) and Matutuíne/Bela Vista (Southern area) involving local communities residing there.

This article consists of a summary, an introduction, and the main body, which we deals with local knowledge and "socio-cultural aspects related to them" and about "the local community knowledge and the teaching of Natural Sciences". At the end of this item we try to bring an exercise regarding didactic transposition with an illustrative example of Biology. After that, we present concluding remarks (preliminary) because we believe that it is still an ongoing research. In the end, we present the "Bibliography".

\section{The Knowledge of Local Communities: In Search for Social-Cultural and Anthropological Perceptions}

\section{Concept of Local Communities}

Before discussing about the meaning to be attributed, in this research, the term "local community", we will first discuss the concept of community.

In early Latin the term "communitas" which comes from "cum + munus," where the "cum" particle means "together" and "munus" "task" it had the connotation of an abstract noun of "comradeship", "community of feelings" and in medieval Latin, the term acquired a connotation of a 
concrete noun, meaning "group of fellow citizens".

Historically, the concept community it has its genesis from the opposition between the primitive and the civilized terms.

Such opposition inspired from classical antiquity, a series of works from the pre-ethnographic framework, which had as a background, to speculate around the lives of people seen as exotic, as these had different customs of adopted by Greek-Roman civilization. This led to the dissimilarity between "rural" and "urban", the former of which had the connotation of "primitive" and the latter meant "civilized", though both occupied the same continuum community versus society.

In this continuum, the community was dominated by natural or essential will and the society by rational will. The first originates in temperament, character and human habits, while the second, the will was dominated by reason.

From this angle of vision, the concept community is associated with a human group that develops their life together on the basis of ideas and feelings shared by all its members. Thus, these are striking features of the community, the ties established between mother and child, husband and wife, and brothers and sisters. In such associations there are no conflicts of authority and power, they are consensual, just as the economy is based on collective ownership of the means of production and goods.

WEBER (1998: 33) defines the community as a social relationship where the attitude of its members is based on subjective emotional feelings or traditionally aimed at building a common good.

Society, unlike the community, is conducted by the predominance of rational will, each individual sees himself as the ultimate focus of concern, encouraging a kind of hostile behaviour to other members of the group. This is how the above author defines the society as a social relationship in which the attitude of its constituents is based on a compensation of interests for rational reasons, purposes or values.

Historically, the community preceded the society, since the community has its genesis in relationships based on family life and in the domestic economy, whereas society emerged from the development of city life, based on trade and contractual relations, where the keynote was the rational use of capital and labour and increased industrialization, following the development of States and of national life.

Now the focus in this research, as already mentioned, is to rescue local knowledge. And this knowledge is mostly in rural areas where the inhabitants practice basketry, agriculture, crafts, fishing, among other activities, as a means of subsistence.

In them, what prevails is the relationship of cooperation and solidarity, where the profit, if any, is placed on the secondary level.

For WEBER (1998), a community can be based on all sorts of grounds: an affective relationship; in an emotional relationship; erotic; pity; a united people by relationship of camaraderie and numerous other reasons. Depending on the type of relationship, he distinguishes various types of community: family, domestic, economic, ethical, political, to name only a few.

Depending on the definition of Weber of community, it is reasonable to say that for this research we are in the presence of various types of communities, depending on the type of activities they developed: in Magude, one is in the presence of traditional leaders community, Motaze Locality; in Kalanga we are with Chekwa Locality community in Bela Vista, with community Missevile Locality.

And as such communities occupy a defined geographical area, a geographical area related to the site; they receive in this research the generic name of "local community".

However, the intention is not to remain strictly at local level. The intention is to use the knowledge of these communities in a more socializing level, through the appropriation of their knowledge for school knowledge.

As FORQUIN (1993:133) rightly argues, we live "in a modern, complex society", where each community constituent element is connected, "consciously or unconsciously, a plurality of groups has a plurality of status, is confronted with a plurality of models undergo contradictory pressures, different messages."

In this author's view, underlies metaphoric vision of the community as a network. In this image, each member is a thread that makes up the texture thereof. In view of this intricate interfering element in the individual seen as one, we propose an approach that involves developing complex strategies that must be rooted in resources and varied skills.

This complexity is further increased in Mozambique, where, in addition to a national culture, there are also regions (the provinces), and even so, there is an ethno-linguistic diversity and extremely complex and rich cultural. Defending the rescue of local knowledge should not be understood here as a claim of a curriculum differentiation, as this, according to FORQUIN (1993), it is not compatible with the unity of a nation. This author defends the idea that goes into the transmission line to all students from the same country of a minimum of common knowledge and common references and values.

The transmission of this common knowledge, however, in our view, does not mean should be left to the secondary level, the local knowledge those that Geertz (1989:137) prefers to call them "the common sense knowledge" coming in a form of "in the form of epigrams, proverbs, jokes, stories and not in formal doctrines, axiomatic theories, or architectonic dogmas."

Based on this common sense that the primitive developed and systematized sets of empirical knowledge that appeared having no practical use but in fact when well systematized and socialized, can be a pool of valuable knowledge. 


\section{The Knowledge of Local Communities: Symbolism and Mythology}

\section{Symbology}

The relevance in addressing this issue is that, during the empirical research, many words and many actions that we were "given" by local communities do not find at first glance, a reasonable justification, need to enter in the epistemological issues.

Starting with the category "symbol", it can be said that this plays four main characteristics as follows:

a) It holds an identity relationship which symbolises: For example, in the community of Missevele in Bela Vista, we were told that "when you are in the bush looking for honey, certain birds accompany you to the location where there is honey as guide, just follow them to the location where they fly. This bird is called "Xalala". According to the community "... The secret for the next successes is that, after harvesting the honey, they should leave in place a reasonable amount of honey for the bird to eat. If you fail to do that, for any reason, the next day, when you want to harvest more honey, the bird will guide you, instead of leading you to the place where there is honey, it will lead you to a dangerous place and can be attacked by a swarm of bees or a mamba snake ". This means that leading the bee hunter to a danger spot symbolizes "bad luck" for those who do not comply with the "community standards." This means that in the strength of the fullness of "evil spirits", the symbol is what symbolizes the action of danger.

b) The interviewed communities have always evoked that whatever they do is with the help of the spirits of their ancestors. In this extreme fervour of belief, the spirit is the catalyst strength; similarly, in the presence of misery, it is attributed to the spirit the responsibility of the fact that, as witness to the ceremonies in the community of Motaze, that before the disgrace in their farms fields were ravaged by plagues of locusts for example, "there is in region a ritual to remove these insects, the granddaughter of the kinglet, in the company of women of the village, carries the locusts in a basket and singing they go towards the river and this walk, they cannot cross paths with men. And if by mere misfortune they should cross way with a man, he would be attacked to the point of removing his trousers. This ritual is called "pfumphanhe". In this walk to the river, the songs that will be singing are in a form of an insult or curse to the pests for them not to return to their farms. This ritual is related to "chasing away evil" and the village, the person in charge of this action is the granddaughter of the kinglet. Another ritual takes place when there is drought or another misfortune in the village. In this case the villagers present the problem to the kinglet and a contribution in cash or in food is made and corn is bought in order to prepare a traditional drink known in the village as "Shinto" or "oputso". Then an animal which may be a chicken or a goat is sacrificed. The choice of the animal type to be sacrificed depends on the type of prayer to accomplish. After killing the animal they cannot be cooked: they can only be grilled. This ritual is called "kupatxa". Here, the symbolic power is that evoking the spirits by means of songs and the "kupatxa" ceremony, so that they do not create future misfortunes to the village.

c) The use of symbols does not depend on the formal logical rules and categories of empirical rational thought: Indeed, the absence of this conceptualization is what facilitates its use in the communities.

d) The symbol has often a feature and a community function. In this case, it is significant of a social structure to which it belongs: A kinglet in a community is holder of a symbolism that relates to the local authority. It is based on these characteristics that can defined the symbolic thought that is rooted in local communities that are the subject of this research, as related to that thought which develops from function of symbols and has the virtue not only of giving rise to concrete and rich presence evoked in them, but also to understand and uncover the truth in them involved. And this "revealing the truth" is manifested in the case of local knowledge, using the expression from CAMPBELL (1999:62), "...from experiences of people in a given community at a given time and space."

\section{Mythology}

As for the myths that are rooted in local knowledge, they manifest themselves in many ways, and in all of them the common thread is that of it represents a metaphor of what lies behind the visible world. As metaphors they are "...stories of our search for truth, of meaning, of significance, through the ages..." (Campbell 1999: 62).

When this research scrutinizes the knowledge which communities hold, with the aim to redeem them for school knowledge, we are faced with this search for truth, of meaning, of significance about who we are, where we came from and where we go. In this question, particularly in relation to "where we come from," the myth helps us to meet ourselves as they represent the "return to the womb" of our mother, to use the words of ELIADE (2000).

Indeed, "one cannot perform a ritual, unless one knows his 'source', that is, it is the myth that tells how it was made for the first time ..." (ELIADE, 2000:20).

In the prayer that Motaze farmers make in the first harvest of rice; in the "pilgrimage" that this same community does to the places of worship in the woods in the area known as "Sikanhana Sacaka N'gwenha", named 
after the local kinglet, which is used as a place where they often go for the purpose of evoking prayers, the spirits of the region, these prayers that are known locally by the name of "Chivevene" in which for example in case of prolonged absence of rain they make "Chivevene" for the rain to appears; the ritual of death in Chékua community in Kalanga, where we learned that in the event of any family member does not comply with the rituals of the region, and that family member preferably one of the spouses "caught" tuberculosis; furthermore in the same region, the ritual consisted in the fact that when he died someone in the village and had his family: father, husband or other kinship working in the mines of "Rand" in South Africa, when he came back after the death of one of the family, he was given a 'xima ", wrapped in traditional medicine and only after eating this" xima", that's when he could be involved in the death ritual; in the community of Missevele in Bela Vista, there is an episode that mentions that when, for example a cat hunting a bird and brings it home, it is advisable not to eat the bird. If in case, the man of the house or another family member eats the bird, it may happen that night the cat as a form of revenge, instead of hunting a bird, may go to the woods in order to hunt a snake and to leave it in his neck while he sleeps; in all these cases the communities do nothing more, nothing less than to repeat the same ritual first carried out by their ancestors. In these examples, when individuals repeat the mythical gestures through the rituals, they become a contemporary of the ancestors, implying that

They stop living in chronological time, and start living in the primordial Time, in the Time when the event took place for the first time. That's why you can talk of the "strong time" of the myth: it is the prodigious time, "sacred", where something new, strong and significant was manifested fully. Reliving this time, reinstate it as often as possible, re-watch the spectacle of the divine works, rediscover the supernormal relatives and relearn their creative lessons is the desire that can be read in all the rituals reiterations of myths. (ELIADE, 2000:22).

In this search, who are we after all? In this search made possible through knowledge of local communities, can be distinguished, according ELIADE (2000), in four functions of Myth:

a) Mystical function - which consists of opening the individual makes to the world to the dimension of the mystery to the mystery of consciousness. This occurs, for example, when we grieve before any misfortune, we do prayers for help from the supernatural being. This was visible in the various testimonies of the interviewed communities, when alluding to cases in which, when faced with natural disasters, environmental disasters or even bloody wars they "were asking for protection from to Supernatural Being";

b) Cosmological Function - consisting of the scale according to which science is concerned with showing what form is the universe. This function is one that often makes us think that scientists are people with answers to everything in the universe. Not quite: there are facts that the day-to-day communities do not find any answer in the "science". Otherwise, how to explain for example the ritual of "pfumphanhe" in Motaze community that after they carried out the plagues they "disappeared" from their fields? This act does not find an answer in the modus vivendi of the "civilized world";

c) Sociological function - which is to make valid a certain social order. In this function, the myth varies from place to place. In the three communities that are the subject of research of this work (Chékua / Kalanga, Motaze / Magude and Missevele / Bela - Vista, we found that although rituals carry similar traits, there was something particular which was characteristic of each community.

d) Pedagogical function - this teaches us how to live a human life under any circumstances. The example is the initiation rites, we found in the three communities that are objects of this research work, which introduce either the girl or the boy in adult life, through what ELIADE (2000) prefers to call as "return to the womb", alluding to the fact that when making the initiation rite, recapping what was done first by our ancestors, we have,

(...) Aimed at introducing ritually (...) in the sacramental reality of the world and culture, and thus validate the new existence, proclaiming their compliance with the mythical paradigms. Not only that, the child (...) is placed in the face of a series of beginnings. And you cannot 'get' something unless you know its origin; you know how this thing came into existence for the first time. (ELIADE, 2000: 35).

Although the four myth functions here bearing the importance it is the pedagogical one that is intended to give a larger dimension, since the pedagogical myth function permeates almost all the testimonies that appear in this empirical research which often witnessed that when communities were surveyed, often referred to the transmission of knowledge, it was acquired from generation to generation.

\section{The Knowledge of Local Communities: Models, Imagination and Imitation}

Still in the discussion on the relationship between local knowledge and sensations "found" in local communities, it is important to make an inference from this knowledge with symbolic models, with imagination and imitation that were feelings that came to light when research was conducted. 
The symbols and myths analyzed in the previous section are interconnected with the models, with the imagination and imitation.

Regarding models GEERTZ (1989: 96) argues that,

(...) In a man, neither the predominant areas of mental sets can be formed with sufficient precision in the absence of guidance by the symbolic models. To make our decisions, we need to know how we feel about things; to know how we feel about things we need public images of feelings that only ritual, myth and art can provide.

In this regard, it is noted that there is an overlap between the nervous system and symbols, in that the human nervous system is due to the access that this has in public symbolic structures that allow building their own independent continuous activity patterns.

In the case of local communities dealt with in this work, public symbolic structures are, among other artefacts, tools, hunting, family organization and in sequential order, art, religion and 'science'. These are symbolic structures that shape somatically the villager. These are necessary, not only to survive, but also to their existential realization.

For local communities, the main rituals of religion, an evocation of the spirits for example, or a pilgrimage or even a dance, are symbolic models, if we look at them more as activities than the words themselves.

The development of thought by the villagers of local communities is also due to its imaginative power, defined as the thought that builds environmental image.

A typical model example, we find in the community of Motaze where mr. Vasco Eliasse Makovele, a healer by occupation, he built the local Primary School using his own resources.

Imitation is another option that can associate with the model. Indeed, in Motaze community, we saw several followers of Mr. Vasco Eliasse Makovele, on the path of healer. And they do it by "imitating" his steps. Indeed, thanks to this power that explains why around Vasco Eliasse Makovele's house we found several makeshift huts as "schools" where his disciples were initiated in the art of "healers".

MATURANA and VARELA (1995: 225-226), stress that it is not easy to explain what is imitation in terms of nerve physiology, but they are of the opinion that it is through this phenomenon that allows a certain mode of interaction that exceed ontogeny of an individual and remain more or less invariant over successive generations, and such interaction includes,

(...) The entire set of communicative interactions of ontogenetic determination that allow certain invariance in the group's history, going beyond the particular history of the subjects. Imitation and ongoing intragroup behavioural selection then play an essential role, as they make possible the engagement of young people with adults, specifying a certain ontogeny which is expressed in the cultural phenomenon.

We find this imitation in dances performed in Chécua communities; in Kalanga, in the rituals of death evoked by Missevile community in Bela-Vista; in perpetuating the ceremony chase the pests in the fields, the "Chivevene" in Motaze community in Magude, just to mention a few examples. All this finds its explanation in the fact that the communities possess a paradigmatic imitation capability, as this imitation has a positive aspect to be attached to the myth that "... it forces man to transcend his limits, forcing him to locate himself next to the gods and mythical heroes, in order to carry out their acts ... "(ELIADE, 2000: 128).

The mythological thinking has two paradigms and two modes. The first paradigm is the intelligibility of the living, not the physical, by single, not the general, by the concrete, not by the abstract.

This paradigm, in the case of local community knowledge is expressed for example when the elders tell their stories on moonlit nights and around the fire to their young, identical process to that for example we were told in Missevile community, on wars of occupation occurred in bygone days. About it, they told us that:

In times long gone, there were rival tribes and that they could not live side by side. The more vigorous tribes are the ones that possessed the best land, the most arable and the other less powerful tribes were "pushed" to inhospitable regions. And there were tribal wars and the winning tribes enjoyed broad powers. These tribes were for example "machanganas" and that "mabinguines", "mandaus," makuas," they could not join among themselves. Who won kept the best land, the best food and the leader of that tribe could choose the most beautiful women of his tribe and other tribes. Women in quantity and quality "- so they told us.

These elders, in their narrative, did not resort to abstract causalities but the living entities that, through concrete measures and specific events, created a world, giving rise to the phenomena and thus build the story.

In this narrative, the elders took ownership of what Geertz (1989:143) refers to the ethos of a people, defining it as "the tone, character and quality of their life, its moral and aesthetic style and his willingness (..) the underlying attitude towards himself and his world that life reflects "to" represent a type of life implicit in the state of real things. "

The second paradigm is related to the general semantic character that myth entails. This character eliminates all that is meaningless and gives meaning to everything that happens.

And to make sense of myth just relate it to its origins. This is what happens, for example, in local communities when a particular event is related to Supernatural Being. It is common to hear in these communities the designation of "God of the storm," "God of Rain", "drought from God," "God of love" and many other "gods". When there is storm, it is this "God" that allows prayers, ask for a more serene time and there is dry, it is the "God" of the drought who are 
asked for the rain with the following prayer, for example alluding ELIADE (2000:87) when he says: "oh heaven, to whom we owe grace, great is the drought; make it rain, so that the earth cools off and that the fields prosper."

Magic is another concept worth highlighting, as it is present in local communities. It intervenes where there is desire, fear, luck, risk and chance. Magic is a power that is exercised by practical own rituals and covers a huge field of action: action at a distance over the living or on natural forces, subject to spirits or genius, ubiquity, metamorphosis, healing, curse, divination, prediction.

As the myth, magic is intrinsically linked to the symbol. Here, the power of appointment is very relevant, since the name has the power to evoke the thing named. And this power of the word to name is reserved for witches or wizards. It is for this reason that we find in communities testimony related to names that attach to children to ancestral loved ones. This is due, according to the interviewees:

(...) The names of the people have a dual connotation: there is a childhood name and the registration name. For example, Mr. Samo, for him, this is childhood name, but in the registry is Arthur. But there is another name, which is used in the neighbourhood that is Mfukwa, which in local language means resurrect. To assign the traditional names there is first a consultation to the healers and after that the name is attributed, because if this not done so according to this rule, the child runs the risk of becoming ill or even die. The assignment of names also obeys the order of generations. But someone can bear two or more names. (CHÉKUA COMMUNITY / Kalanga).

Magic, as myth, are rooted in socio-anthropo-cosmic paradigm, comprising the following features:

a) Magic is based on analogies to the figurative; images and dolls;

b) These analogies are used to operate individual, local or legal metamorphoses;

c) Magic uses in its rites, often, mimesis, which also receives the name of "natural magic."

Examples of these features are plenty with the healers. Thus, the needle during a "consultation" is poking at some direction (virtual) of a doll, at that precise moment is creating a real injury in the person figured by the little doll.

For local communities, subject of this work, mimesis is used, according to statements of the interviewed, in the dances and hunting rites of war and fertility.

In local communities referred to in the present work, the mythological and magical power is used frequently, either to cure or to witchcraft. In the first case, receiving the generic name of traditional medicine, in many cases, it generates miraculous feats that surpass the achievements of official medicine.

Redeeming this knowledge to the official knowledge does not seem an easy task, especially for minds like ours, full of other preconceptions about science. But Geertz (2000:91) suggests that to overcome this and understand other people's ideas "requires that we put aside our design, and seek to see the experiences of others in relation to their own conception of "I".

\section{The Knowledge of Local Communities and the Teaching of Natural Sciences: In search for a "Didactic Transposition": The Case of Massala}

\section{The Knowledge of Local Communities on the Use of Massala}

In the community of Chékwa in Kalanga, District of Manhiça we interviewed local communities about the healing power of some native plants and one that was mentioned was massala whose roots are said to cure stomach aches. We asked then how the people (in the community) could take ownership of plants and relate them to cure. And the answer was: "Our ancestors had spirits, "chikwembos". When the spirit is released, who is going to the bush it is not the person himself: this person has embodied a spirit that goes to the forest and harvest the plants. It is from the gift of spirit. This usually appears in a dream that tells the person which plant should be harvested in the bush and what its function in healing is. In the dream the person is "indicated" where in the bush the plant is located. So during sleep, it usually appears on the bedside at the plant and the disease that heals. Moreover, the experience of the people who deal with this practice is also crucial. The lack of hospitals in the region at the time also was a greatly determinant in this search.

\section{School Knowledge of Massala}

This follows that describe content, it can be taught in the subject: Natural Sciences; Grade 6; Thematic Unit: Plants; Contents: "The plants in the communities and their characteristics"; "Importance of plants"; "Agricultural techniques"; "Other measures employed in agriculture"; "Reproduction of plants" and "plant conservation"; in the general secondary education, can be taught in the subject: Biology; grade 11, in the Thematic Unit: Kingdom of Plants; whose contents are: "Plant Classification": "Vascular Plants - Division of Traqueofitas".

Some of the content:

The scientific name of massala is Strychnos spinosa. And the common names are: Spiny Monkey-orange / Green Monkey Orange (English), Doringklapper (Afrikaans), Morapa (NS), Muramba (V), umKwakwa (Swaziland), Nsala (Tswana), Mutamba (Shona), 
Strychnos spinosa (Angola). The following images illustrate the massala:

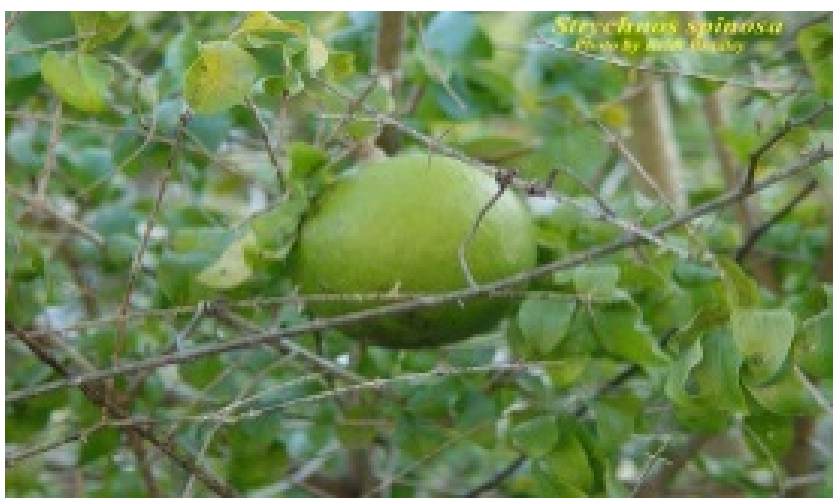

Figure 1. a). Strychnos spinosa plant

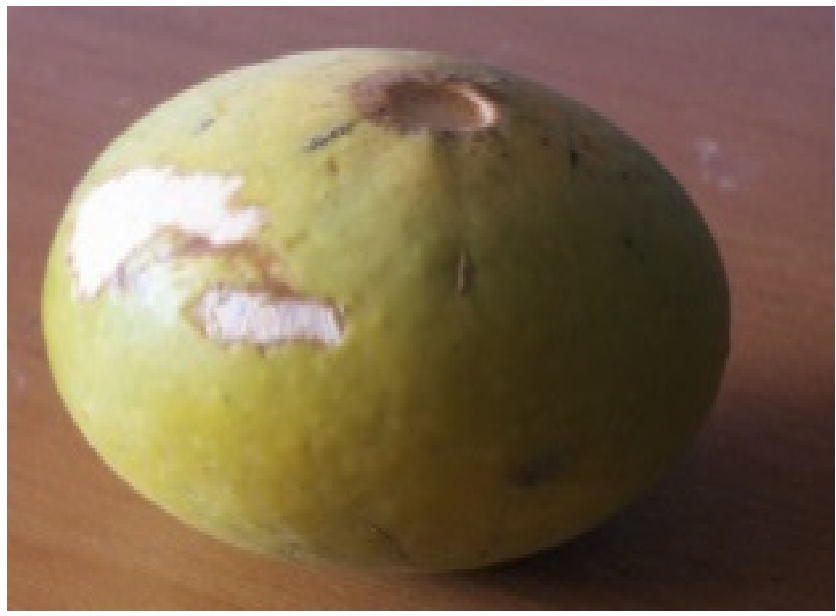

Figure 1. b). Strychnos spinosa fruit (mature)

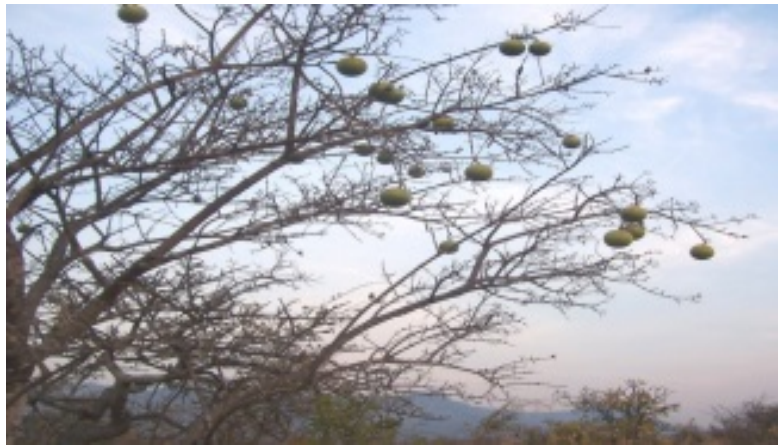

Figure 1.c). A tree Strychnos spinosa

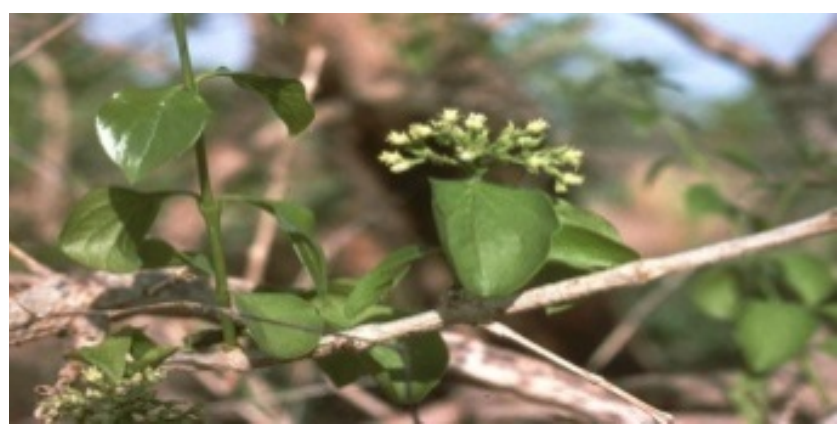

Figure 1.d). Flowers of Strychnos spinosa

As for the Habitat, it is said that massala, or "Strychnos spinosa Lam," is a native tree that abounds in tropical and subtropical regions of South Africa, its flowering occurs in spring -. Summer. As for the description, massala, or "Strychnos spinosa Lam is "armed" in a form of shrub or small tree. Their stems are not very thick. Often the stems are peeled and elongated pieces, but not deeply fissured. The branches are slightly pale and stained, usually hairless, often ending in a terminal spine. It is also armed with axillary curved spines or straight. It has elliptical leaves, oval, almost circular, with or without short hair and a very bright dark green colour, dull, whitish on the underside, often slightly wavy on the boarders; It has a stem length up to $10 \mathrm{~mm}$. The colour of flowers is "green and white" and shaped head, are compact and dense, ending in the main branches or the short side strips.

\section{REFERENCES}

[1] CAMPBELL, Joseph, with MOYERS, Bill. (1999). The power of myth. 17th ed, São Paulo, Pallas Athena.

[2] ELIADE, Mircea. (2000). Myth and Reality. 5th ed, São Paulo, Perspective.

[3] Forquin, Jean-Claude. (1993). School and Culture: social and epistemological foundations of school knowledge. Porto Alegre, Medical Arts;

[4] Geertz, Clifford. (1989). The Interpretation of Cultures. Rio de Janeiro, Publisher Affiliate;

[5] Maturana, Humberto \& VARELA Francisco. (1995). The tree of knowledge. São Paulo, editorial Psy II,

[6] WEBER, Marx. Economy and Society. (1998) 12th ed., Mexico, efe. 